\title{
THE USE OF A PRECIPITIN TEST TO DETERMINE HOST PREFERENCES OF THE VAMPIRE BATS, DESMODUS ROTUNDUS AND DIAEMUS YOUNGI
}

\author{
by \\ ARTHUR M. GREENHALL 1) 2) \\ Bat Ecologist - Food and Agriculture Organization of the United Nations, Rome \\ Research Associate, Smithsonian Institution, Washington, D.C., U.S.A.
}

\section{INTRODUCTION}

Vampire bat rabies is one of the greatest deterrants to the raising of livestock in Latin America. To know more of the epizootiology of the disease as well as to understand the ecology of the vampire bat family, Desmodontidae, detailed information about their feeding habits and host preferences is essential. Vampire bats feed exclusively on blood. Examination of probable host animals for bat bites has been the primary method used to determine their victims. More reliable precise data are achieved by serological analyses of the digestive tract contents of vampires killed after attacking their hosts. Precipitin test techniques were used similar to those devised for the identification of blood meals of bloodsucking arthropods (Weitz, 1952, 1956, 1960; Tempelis \& Lofy, 1963).

If the exact domestic as well as wild animal host preferences of vampire bats were known, this knowledge could assist in their control and might indicate other hitherto unsuspected hosts.

Since the digestive physiology of the Desmodontidae is not well understood, it was necessary to determine whether the method used for the identification of blood meals of bloodsucking arthropods would be satisfactory for vampire bat studies and how long blood meals would be identifiable in the bat's digestive tract. To answer these questions, an experiment was conducted on January 9, 1961, in the Trinidad Regional Virus Lab-

1) FAO/UNDP/SF Research on Paralytic Rabies Project - MEX 16 Instituto Nacional de Investigaciones Pecuarias, Palo Alto, Mexico, D.F.

2) Project Contribution No. 5. Paper presented at the Second International Bat Research Conference, Amsterdam, The Netherlands - March 20, 1970. oratory using Desmodus rotundus, the vampire bat most involved with the transmission of rabies.

\section{MATERIALS AND METHODS}

Twenty four vampire bats were collected alive by the bat collecting crews of the Government of Trinidad and Tobago (which has been conducting a vampire bat destruction programme since 1934) and brought to the laboratory on December 13, 1960. They were housed in six cages, four bats to a cage, and fed daily on the usual maintenance diet of defibrinated cattle blood.

To clear their digestive tracts before the beginning of the experiment, the bats were starved for three days, which according to personal experience and the literature is the longest period that Desmodus can remain alive without feeding. Some of the starved bats would not drink the test bloods when offered. Five refused to feed for as long as $881 / 2$ hours - a record. The test therefore, had to be recycled.

The protocols of the experiment required that 24 vampire bats, Desmodus rotundus, be fed for 15 minutes on two serologically different defibrinated bloods, ox and sheep, 12 bats to be fed on each kind of blood. The blood meals were offered in sterilized dishes. No drinking water was provided. On January 9, 1961 all 24 bats fed for the required 15 minutes as planned.

After 15 minutes the dishes containing the two blood meal types were removed from the cages. Next, one bat from each group (ox blood and sheep blood; was sacrificed at intervals of: $15 \mathrm{~min}$ utes, 30 minutes, $1,2,4,8,12,18,24,36,48$, and 72 hours. Blood meals were then dissected from the stomach and intestines, using sterilized instruments, one smear each from stomach and 
BIJDRAGEN TOT DE DIERKUNDE, 40 (1) - 1970

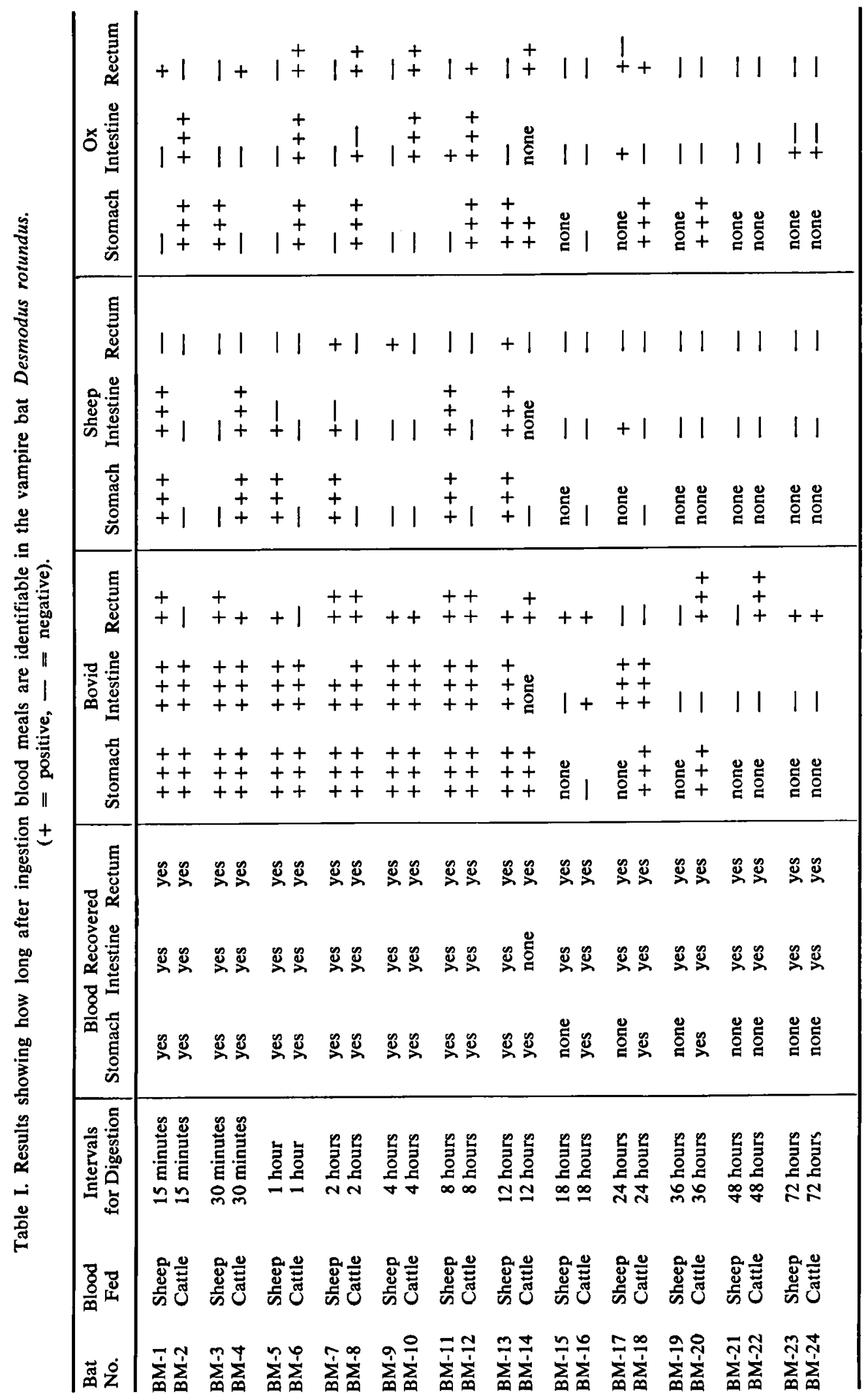


intestines was placed on a single circular filter paper, 9-10 cm diameter (Whatman No. 1), identified by a number and thoroughly dried, following techniques described by Weitz $(1960,1963)$. The samples were sent by airmail to the Lister Institute for Preventive Medicine, England, for testing.

Anti-Bovid, anti-Ox and anti-Sheep, specific antisera were used in the serological tests. The smears were cut out from the filter paper and the pieces bearing the smear were diluted in $0.5 \mathrm{ml}$ of physiological saline in individual tubes, which were allowed to stand at $+4^{\circ} \mathrm{C}$ overnight. These extracts were then tested by the precipitin-ring test using different antisera in small capillary tubes and employing the apparatus described by Weitz (1957). After 2 and 4 hours incubation at room temperature the tests were read and recorded.

Table I gives the results of the identification tests of the blood meal smears. The meals all reacted specifically with the respective antisera and all reacted with the anti-Bovid serum which gave a more sensitive reaction in view of its higher titre. The time during which the blood could be identified varied according to the sensitivity of the antisera used. Anti-Bovid serum, which reacted with both the blood of ox and the blood of sheep was more sensitive and therefore gave positive reactions for longer periods after feeding time, than the more specific but less sensitive anti-Ox and anti-Sheep sera.

The blood persisted in the stomach of all bats for 12 hours, while two bats fed on ox blood contained blood in the stomach for 24 and 36 hours respectively. Digested blood appeared in the intestine of all bats in 15 minutes or less and persisted for at least $\mathbf{8}$ hours after feeding, and in two bats for 24 hours.

Positive rectal smears were obtained as early as $\mathbf{1 5}$ minutes and in some cases persisted as long as 72 hours. The positive reaction of the rectal contents at the early stages may have been due to a carry-over from the maintenance diet of the captive bats before the experiment started. For example, bat BM 1 was maintained on cattle or ox blood and then starved for $621 / 2$ hours before the experimental feeding on sheep blood. The rectal contents of this bat were positive for both antiBovid and anti-Ox sera at 15 minutes indicating a persistence of the maintenance diet. Thus any positive rectal smears up to 1 hour after experimental feeding may have been the result of previous feedings and should be disregarded. This is confirmed by the presence of positive intestinal contents 72 hours after experimental feeding of some bats (see bat BM 23 and BM 24).

In general sheep blood appears to have been more quickly digested than ox blood but this might have been due to individual variations. It should be noted that the stomach contents of bat BM 13 reacted both with anti-Ox and anti-Sheep sera, indicating that contamination of the smears probably occurred during dissection.

Thus the precipitin test used for identifying blood meals of bloodsucking arthropods can be used successfully to examine digested blood taken from the gastro-intestinal tract of Desmodus rotundus and indicate which animals the bats had fed upon. It further shows that bovine and sheep blood meals in the stomach can be identified for periods between 24-36 hours, and that rectal smears are identifiable up to 72 hours after feeding.

\section{DESMODUS ROTUNDUS IN TRINIDAD}

My studies of the host preferences of Desmodus rotundus in Trinidad using the Weitz technique of identification based on about 3000 samples, indicated that Desmodus feeds upon a wide variety of domestic animals, bovines preferred, and that the bats had also fed upon a number of unidentifiable wild animals. Unfortunately antisera to test against wild hosts in Trinidad were not available.

\section{DESMODUS ROTUNDUS IN MEXICO}

In Mexico, using the Tempelis technique based on about 500 samples of Desmodus rotundus feeds primarily upon cattle, varied with a very small number of other domestic animals. Further testing from a variety of areas will present a clearer picture for Mexico. The results of the first small study in Mexico in which 14 samples of blood meals from the gastro-intestinal tract of nine Desmodus showed that:

5 bats had bovine blood in the stomach and intestine;

4 bats had fed upon wild or domestic animals other than bovines;

3 bats had fed upon more than one host, i.e. bovine, unidentified mammal and man;

2 bats had the blood of one host in the stomach and a different host in the small or large intestine, i.e. bovine and unidentified mammal in the stomach and bovine and man in the small or large intestine. The bat feeding upon man confirmed reports that in this area children had been bitten by vampires.

1 bat had bovine blood in the stomach but the intestines were negative consistent with a hypothesis that Desmodus do not need to feed every night. 


\section{DIAEMUS YOUNGI IN TRINIDAD}

In Trinidad our previous observations on Diaemus youngi, the white-winged vampire bat, showed that this vampire preferred avian to mammalian blood (Goodwin \& Greenhall, 1961). In fact, captive Diaemus refused to drink cattle blood in the laboratory, although they fed upon the blood of goats, donkeys and guinea pigs. Some time after our blood meal collections had started, I investigated and confirmed an unusual observation that Diaemus had been attacking cattle! In view of our unsuccessful attempts to feed Diaemus on cattle blood, this was a startling observation. Of a total of 23 adult Diaemus tested using the Weitz method 13 had fed upon mammalian blood, i.e. bovid, pig and some unidentifiable mammals in various combinations. Of the remaining 10 bats, eight had fed upon avian blood in combination with mammalian blood and only two had fed exclusively on avian blood. These findings are significant since they indicate the importance of using host preference tests in studying vampire life history as well as suggesting that in Trinidad, Diaemus may be undergoing a change in diet. Since Diaemus has been found to be rabies positive in Trinidad and is apparently becoming more numerous, it may in time become as serious a danger to livestock as Desmodus is now (Greenhall, in M.S.).

\section{DISCUSSION}

Further tests should be conducted with blood meals of different species of animals to determine the length of time that they may be identifiable. It is possible that by the examination of faecal material collected in vampire bat roosts the origin of natural blood meals might be detected for extended periods. In addition faeces collected from daytime roosts or in the digesting places which vampires use as temporary resting stops during the night, before they retire to their regular daytime roosts, could possibly be used for identifica- tion of the hosts of these bats. With this information it might be possible to determine the frequency and intensity that animals may be attacked by vampire bats within a given area. If the blood meal results show that cattle are almost entirely attacked in a specific area, then the number of bites seen on cattle would give some indication of the size of the vampire population within that area. In those areas where vampire bats feed upon several different hosts, either domestic or wild animals, in a single night or within several days the number of bites seen on cattle would not necessarily give an indication of the vampire population. In any event, care must be exercised in estimating the vampire population from simply counting the number of bites seen on cattle - since a number of bats may feed upon a single cow in one night.

The principitin test used for the identifying blood meals of vampire bats is important in finding unsuspected hosts or reservoirs of rabies among species of wild animals fed upon by these bats. However, this useful research technique requires a bank of sera collected not only from all the domestic animals but also from those tropical wild mammals, birds and possibly reptiles and amphibians, found in the same areas as the vampire bats for making anti-sera used in the precipitin test.

\section{ACKNOWLEDGEMENTS}

I am grateful to Dr. Wilbur G. Downs of the Rockefeller Foundation and former Director of the Trinidad Regional Virus Laboratory for providing laboratory and office space as well as making the necessary arrangements with Dr. Bernard Weitz, of the Lister Institute of Preventive Medicine, England, who kindly undertook the testing of vampire blood meals used in the initial Trinidad experiment as well as other tests made on Trinidad vampire bats. Dr. C. H. Tempelis of the University of California, Berkeley, kindly tested the blood meals from the vampire bats collected in Mexico. I thank Mr. Franklin T. Thurab, Anti-Rabies Assistant (Laboratory), Ministry of Agriculture, Trinidad and Tobago who assisted with all phases of the initial experiment and diligently cared for the live vampire bats.

\section{LITERATURE CITED}

Goodwin, G. G. \& A. M. Greenhall, 1961. A review of the bats of Trinidad and Tobago. Bull. Amer. Mus. nat. Hist., 122 : $187-302$.

Greenhall, A. M. (In M.S.). Host preferences of the white-winged vampire bat, Diaemus youngi in Trinidad.

Tempelis, C. H. \& M. F. LoFY, 1963. A modified precipitin method for identification of mosquito blood meals. Amer. J. trop. Med. Hyg., 12 : 825-831.

WEITZ, B., 1952. The antigenicity of sera of man and animals in relation to the preparation of specific precipitating antisera. J. Hygiene, 50 : 275-294.

—, 1956. Identification of blood meals of blood sucking arthropods. Bull. Wld. Hlth. Org., 15 : 473-490.

-, 1957. An automatic dispenser for multiple serological titrations. J. clin. Pathol., 10 : 200-207.

,- 1960 . Feeding habits of bloodsucking arthropods. Exp. Parasit., 9 : 63-82.

- , 1963. The feeding habits of Glossina. Bull. Wld. Hlth. Org., 28 : $711-729$. 